\title{
Framing in a Threshold Public Goods Experiment with Heterogeneous Endowments
}

\author{
Kjell Arne Brekke ${ }^{1}$, James Konow ${ }^{23 *}$, Karine Nyborg ${ }^{4}$
}

\begin{abstract}
In cooperative endeavors among economically heterogeneous parties, the contribution decisions can often be framed in different ways. But do such framing differences affect behavior? We report the results of a laboratory experiment on threshold public goods with heterogeneous endowments and different frames. Four treatments frame the contribution metric either in absolute terms or relative to endowments, and the contribution choice as either keeping or contributing some of one's endowment. Subjects can exchange proposals and counterproposals. We also collect data on fairness preferences. Our results reveal a broad consensus, which we trace to subjects' distributive preferences, that high endowed subjects contribute more in absolute terms than the low endowed. Both high and low endowed subjects contribute about twothirds of their endowments in all treatments - save when the metric is framed as "contributing" in "absolute" terms: then the low endowed contribute significantly more, around $80 \%$. This last result might indicate that the frame most frequently used in public good experiments induces higher contributions among the less affluent than economically equivalent alternate frames.
\end{abstract}

Keywords: Cooperation, framing; heterogeneous endowments; threshold public goods; fairness

JEL codes: H41, D63, C92

\footnotetext{
${ }^{1}$ Department of Economics, University of Oslo, P.O.Box 1095 Blindern, N-0317 Oslo, Norway. E-mail: k.a.brekke@econ.uio.no.

${ }^{2}$ Chair of Economics and Ethics, Kiel University, Wilhelm-Seelig-Platz 1, D-24118 Kiel, Germany.

${ }^{3}$ Department of Economics, Loyola Marymount University, One LMU Drive, Suite 4200, Los Angeles, CA 90045 2659, USA. E-Mail: jkonow@lmu.edu.

${ }^{4}$ Department of Economics, University of Oslo, P.O.Box 1095 Blindern, N-0317 Oslo, Norway. E-mail: karine.nyborg@econ.uio.no.

*Corresponding author: Department of Economics, Loyola Marymount University, One LMU Drive, Suite 4200, Los Angeles, CA 90045-2659, USA. E-Mail: jkonow@1mu.edu.

We wish to acknowledge the helpful and constructive comments and suggestions of Geir Asheim, Etienne Billette de Villemeur, Alexander Cappelen, Richard Cookson, Astrid Dannenberg, Simon Dietz, Werner Güth, Steffen Huck, Stephan Kroll, Jo Thori Lind, Justin Leroux, Amnon Rapoport, Erik Sørensen, Christian Thöni, Asbjørn Torvanger, Bertil Tungodden, and participants at numerous workshops and conferences. This work is part of the project 3171 SAMFUNN: Norms, green agents and environmental policy at the Ragnar Frisch Centre for Economic Research. We are grateful to the Research Council of Norway for funding through the Miljø2015 programme and Kenneth Birkeli for excellent research assistance. All authors acknowledge the support of the Centre for Equality, Social Organization and Performance (ESOP), and Konow also thanks the Centre for the Study of Mind in Nature $(\mathrm{CSMN})$ at the University of Oslo. Brekke and Nyborg are part of CREE (Oslo Centre for Research in Environmentally Friendly Energy).
} 


\section{Introduction}

Cooperation yields mutual benefits in enumerable social endeavors, including in the family, workplace, government, NGOs, and international agreements. Nevertheless, people often disagree, sometimes fiercely, about how much each party should contribute to such endeavors. For example, in wage negotiations between firms and labor unions, both sides prefer to avoid costly strikes or lockouts but have conflicting interests over wages and benefits. Even if all countries prefer an international environmental agreement to be reached, their interests conflict over who should cut their emissions most. Throughout the ongoing Eurozone crisis, EU member states share the goal of preventing a Euro collapse but differ in their views of how to cover the costs of the rescue operation. Although every member of a household prefers clean dishes, each might prefer that someone else wash the dishes. In situations like these, arguments about burdensharing tend to focus on differences in parties' endowments, and, correspondingly, to frame contributions in different ways. For example, in the case of international negotiations to protect the environment, the contribution metric can be framed as a percentage of one's endowment (e.g., emission reductions in proportion to GDP) or in absolute terms (e.g., emission reductions in tons). Similarly, decisions can be framed so as to focus either on "contributing" to the shared goal or on each party's private benefit by avoiding contribution and "keeping" (some part of) its endowment.

The present study reports the results of a laboratory experiment that jointly explores these effects of framing and heterogeneous endowments in a threshold public good game. Public good games are a widely employed framework for theoretical and empirical analysis of cooperation (e.g., see Ledyard, 1995, for a survey of early contributions, and Chaudhuri, 2011, for much of the subsequent work). Nevertheless, no previous study, to our knowledge, jointly analyzes the effects of such framing differences on public goods with endowment heterogeneity.

Our experimental design incorporates various features of the above-mentioned examples. To mirror differences in affluence, we vary experimental endowments between subjects, half of them receiving twice as much as the others. Such endowment heterogeneity sets up possibilities for frames to have differential effects on contributions. Specifically, we frame contributions along two dimensions: the contribution metric is framed either as absolute amounts or in relative terms as percentages of subjects' endowments, whereas the choice is framed as either how much to contribute to the public good or how much to keep of one's endowment. This results in four 
treatments that cross the Metric variable (Absolute or Relative) with the Choice variable (Contribute or Keep) in our 2x2 factorial design.

Since we are interested in burden-sharing, we employ a public good game with a threshold, defining the minimum total burden to be shared. When contributions reach this threshold, there is a discrete jump in group benefits. Whereas the dominant strategy in a linear public good game is to contribute nothing, note that the threshold aspect of a public good game makes it a coordination game: everyone prefers the public good be provided, but there are multiple Nash equilibria generating provision of the public good, each involving different individual burdens.

In standard theory, focal point effects (Schelling 1960, Ch. 3) refer to a supposed attraction to particularly simple or otherwise salient equilibria in coordination games. Treatment effects in our experiment, if any, could be due to an effect of frames on focal points. For example, the mathematically simplest burden-sharing rule in the current experiment is based on the metric of contribution, which varies across frames. A further possibility is that contributions are driven in part by distributive preferences, such as fairness, and that frames affect the interpretation of distributive rules and, therefore, contributions. For example, if subjects consider equality to be fair, then framing contributions in absolute terms could prompt more equal amounts contributed whereas framing contributions in relative (i.e., percentage) terms could produce more equal shares contributed. ${ }^{5}$

Additional features of the design are similarly inspired by the aforementioned examples. First, in contrast to most threshold public good experiments (see Croson and Marks, 2000), excess contributions are not wasted in our study. Although a minimum level of total contributions might be needed to reach an international agreement or to avoid a labor conflict, excess efforts can often improve the public good's quality or quantity: environmental quality improves and the firm prospers. Second, as in real world negotiations, a type of communication is possible. In the experiment, there are multiple "rounds" of distinct targeted outcomes, and within each round, proposals and counter-proposals can be made, as with multiple rounds of negotiations over international environment agreements. Third, parties do not incur the cost of proposed contributions, if the threshold is not met (save a small penalty reflecting negotiation

\footnotetext{
${ }^{5}$ Note that with equal endowments, the meaning of 'equal contributions' would not depend on whether one has absolute or relative contributions in mind. Endowment heterogeneity will thus be an important part of our design, see Section 3 below.
} 
costs). This seems quite natural for a negotiation process involving communication: in the case of a strike, previously communicated wage offers are no longer binding; in the case of an international environmental agreement, offers made during the negotiation process become void, if total pledged emission cuts fall short. Finally, since negotiating parties often motivate their favored burden-sharing claims based on distributive preferences such as fairness, we elicit and analyze these subject attitudes in a post-experimental questionnaire.

We find that groups mostly succeed in reaching the threshold, often by a substantial margin. Subjects tend to agree that High endowed subjects should contribute more in absolute terms to the public good than Low endowed, a robust finding across all frames. Our results point to subjects' distributive preferences as the reason for this. In relative terms, High and Low endowed subjects contribute roughly equal shares, about two-thirds of their endowments, in all treatments save one: when the metric is framed as "contributing" in "absolute" terms, the Low endowed contribute significantly more, around $80 \%$. Thus, the most common practice used in public good experiments, namely framing contributions in terms of absolute amounts contributed, induces the "poor" to contribute significantly more than other economically equivalent ways of framing the choice, at least in the threshold public good context studied here.

The remainder of this paper proceeds as follows. Section 2 presents related literature, and section 3 details the experimental design and procedures. Section 4 presents and analyzes the results, and section 5 concludes.

\section{Related literature}

Here we discuss previous studies, focusing on those most closely related to the main features in our design. ${ }^{6}$

First, various framing effects, i.e., effects of seemingly inconsequential differences in presentation, have been studied in previous public goods games. Nevertheless, to our knowledge, none involves exactly our Metric and Choice frames, let alone crosses the two in a full factorial design. Indeed, with respect to the Metric frame, we are unaware of any public good experiments that employ a "relative" frame, let alone contrast it with an "absolute" frame, despite the

\footnotetext{
${ }^{6}$ Previous studies have shown that public good contributions can be affected by other factors, such as performance on a task and inequality in the distribution of benefits (Balafoutas et al. 2010), endowment inequality and communication (Tavoni et al. 2011), the type of punishment (Noussair and Tan 2011), different time horizons (Milinski, Röhl and Marotzke 2011), threshold uncertainty (McBride 2010) and private vs. common information about thresholds (Fischbacher, Güth and Levati 2011).
} 
prominence of such comparisons of contributions to endowments in, for example, negotiations over international cooperative agreements. The Choice frame in our experiment also appears to be unique, although differences in wording in other studies might be seen as priming a similar focus on the interests of the self vs. those of the group. For example, one of the three significant framing effects in Cookson (2000) is an "I" vs. "we" frame. Rege and Telle (2004) report a weak effect of language explicitly designed to prompt social norms vs. neutral language. Messer et al. (2007) find that contributions vary depending on whether the default setting is giving or not giving, and Andreoni (1995) finds significant effects of positive versus negative framing on contributions (see also Khadjavi and Lange 2015).

Second, previous public good experiments have come to differing conclusions about the effects on contributions of heterogeneous endowments. Buckley and Croson (2006) and Cherry, Kroll and Shogren (2005) find that differently endowed subjects contribute approximately equal absolute amounts in a simple linear public good game with an absolute contribute frame. On the other hand, Rapoport and Suleiman (1993) and Bernard, Reuben and Riedl (2013) study threshold public goods and find that high endowed contribute more than low endowed. The different structure of the studies provides a possible explanation for their differing results: the two former studies are linear public good games, which correspond to Prisoners' Dilemmas, whereas the latter studies are made into coordination games by thresholds. Some studies reporting unequal contributions by endowment, e.g., van Dijk, Sonnemans and van Winden (2002) and Hofmeyr, Burns and Visser (2007), employ relatively small differences in endowments. Our results suggest such differences are robust to larger endowment heterogeneity.

A further question about unequal contributions by endowment is whether the relative generosity of rich subjects represents a "house money effect," i.e., an experimental artifact associated with the fact that the rich receive their higher endowments as a windfall. ${ }^{7}$ The experiment of Cherry et al. (2005) finds little effect of the origin of heterogeneous endowments, i.e., whether windfall or earned; in fact, their results point, if anything, toward greater generosity by the rich when their endowments are earned. In any case, the kind of situations that motivated the current study often involve endowments that are bestowed rather than earned - for example in the case of international cooperation among parties at different levels of economic development, who can be viewed as having had the good or bad luck of being born in a rich or

\footnotetext{
${ }^{7}$ We are grateful to a referee for raising this question.
} 
poor country, respectively.

Third, previous survey studies suggest that distributive preferences are important for real world public goods. For example, Lange et al. (2010) conclude from a survey of real negotiators in climate policy that support for burden sharing rules is based on self-interest and fairness considerations. To explore such motives in an experimental setting, we elicit subjects' distributive preferences, aiming to explore possible roles in explaining any framing effects or endowment-based effects on contributions.

Finally, communication has been found to have favorable effects on cooperation in public good experiments, e.g., Dawes et al. (1977) and Isaac and Walker (1989) identify positive effects of cheap talk. Indeed, previous studies find that making one's own contributions (or intended contributions) common knowledge has a favorable impact on cooperation even in linear public good experiments with no threshold (Messer et al. 2007, Tavoni et al. 2011). On the other hand, Bochet et al. (2006) find that the favorable effects of communication depend on face-to-face communication. An open question we examine is whether individual suggestions about others' contributions affect subject contributions in the present context.

\section{Design and Procedures}

The experiment proceeds as follows. Instructions are handed out and read out loud before the experiment begins. ${ }^{8}$ From the start, subjects are randomly assigned to be one of four members, numbered 1 to 4, of a group. The experiment is double-blind, i.e., subjects are anonymous and decisions cannot be personally associated with individuals by the experimenter or fellow subjects. Subjects 1 and 2 receive a low endowment (L) of 40 Norwegian kroner (NOK), and subjects 3 and 4 receive a high endowment $(\mathrm{H})$ of NOK 80. ${ }^{9}$ Member numbers, and thus endowments, are kept fixed throughout the session as is the make-up of the groups, i.e., we employ a "partner" design. In each round, subjects face a decision about how much to keep for themselves and how much to contribute to a "group project," i.e., the public good. Subjects propose contributions for themselves as well as for each of the other three members of their group. The proposal for themselves is binding, but proposals for others are not. Thus, we will call the former proposals "contributions" and the latter proposals "suggestions." Subjects can try

\footnotetext{
${ }^{8}$ Given the high level of English fluency among Norwegian students, all instructions were in English, a practice that has been employed in other economics experiments conducted in Norway, such as Cappelen et al. (2013).

${ }^{9}$ At the time of the first experimental sessions, $1 \mathrm{USD} \approx 6 \mathrm{NOK}$.
} 
out different proposals and observe the payoff consequences for all members of up to three different sets of proposals before submitting. After everyone has submitted their proposals, all group members are informed of all submitted proposals (i.e., proposals that members try out before submitting their final proposals are not communicated).

In order to familiarize subjects with the experiment, they are first presented with three numerical examples and then complete an unpaid practice round. This is followed by four rounds, all of which are paid, i.e., subjects receive the sum of earnings from all four paid rounds. The practice round is identical to the four subsequent paid rounds, save for the decisions being hypothetical, i.e., the hypothetical stakes are the same as the later real ones, they send and receive suggestions and the results are communicated at the end of the round.

If aggregate contributions (i.e., the sum of binding proposals submitted from each of the four group members) in a given round equal NOK 120 or more (i.e., one half of the aggregate endowments of NOK 240), the group project is implemented: in this case, all contributions are doubled by the experimenters, shared equally by all group members, and the round ends. Thus, a subject's earnings in a successful round are calculated as the individual endowment minus the subject's contribution plus one half of the sum of all contributions to that subject's group (including any possible contributions that exceed the threshold).

Within each round, there are up to three opportunities, or "periods," to submit proposals. The proposals submitted by every member are communicated to every other member in each period, regardless of whether the threshold is met in that period. If the sum of binding proposals submitted in the first period equals or exceeds NOK 120, there are no more periods, the round ends and the group project is implemented. If, however, this sum falls short of NOK 120, there is a second period for all members to submit proposals. If the sum of binding proposals then equals NOK 120 or more, the round ends. If not, subjects have a third and final opportunity to submit proposals. If the total contributions now reach the threshold of NOK 120, the project is implemented; if not, the project is not implemented, and subjects earn their initial endowments in that round minus a penalty of NOK $10 .^{10}$ The experiment then continues to the next round.

The four frames we study correspond to four treatments in our between-subjects design, i.e., each subject participates in only one treatment. These are summarized in Table 1 along with

\footnotetext{
${ }^{10}$ The penalty strengthens the incentives to implement the project. It also ensures that, if the two High endowed subjects contribute 60 NOK each, thus sharing the required threshold contribution of 120 NOK equally, they are strictly better off than if the project fails. The Low endowed always benefit from the project being implemented.
} 
treatment acronyms and numbers of subjects, which averaged 64 per treatment plus or minus 8 due to differences in show-up rates. The "Metric" treatment variable is comprised of the Absolute and Relative frames. In the Absolute contribution frame, the instructions, threshold, examples and proposals are expressed in absolute terms, i.e., the absolute number of NOK. In the Relative contribution frame, these same values are stated as percentages of respective subject endowments.

\section{Table 1}

Experimental design

\begin{tabular}{|c|c|c|c|}
\hline & & \multicolumn{2}{|c|}{ Choice } \\
\hline & & Contribute & Keep \\
\hline \multirow{2}{*}{ Metric } & Absolute & AC, $n=64$ & $\mathrm{AK}, n=72$ \\
\hline & Relative & $\mathrm{RC}, n=64$ & $\mathrm{RK}, n=56$ \\
\hline
\end{tabular}

Notes: Instructions and decisions were framed in terms of the metric of contribution (absolute, relative) and in terms of the choice involving either contributing to a project or keeping some of one's endowment. The contents of cells are treatment acronyms and numbers of observations.

The "Choice" treatment variable consists of the Contribute and Keep frames. In the Contribute frame, the instructions, examples and proposals are expressed in terms of contributing to the group project, whereas in the Keep frame, these same choices are expressed as a matter of how much to keep of each member's endowment.

The Metric and Choice variables are crossed to create a 2x2 factorial design. This means, for example, that the AC treatment expresses values as absolute amounts contributed (the most common frame in public good experiments), whereas the RK expresses values as percentages kept of endowments. Apart from these differences in frames, the experimental procedures are identical in all treatments. The experimental protocol, including instructions, appears in Appendix A.

In an unincentivized post-experimental questionnaire, subjects are asked questions about socio-economic and demographic variables. It also elicits three types of distributive preferences, viz., what subjects consider fair, what they would impose if they could dictate contributions, and what they think each subject should contribute. ${ }^{11}$ The "dictate" and "should" questions permit any values in the feasible range, i.e., 0-40 for Low and 0-80 for High. For the fairness question, each subject is asked to select one set of proposals out of a possible three that he considers most

\footnotetext{
${ }^{11}$ These questions seek to distinguish different levels of distributive preferences from a narrow concept of fairness to broader notions of distribution, as suggested by Johansson-Stenman and Konow (2010, see section 5.3). They also allow for different types of distributive preferences, e.g., Durante, Putterman and van der Weele (2014).
} 
fair. Each of these three distributions (A, B and C), which are illustrated in Table 2, just meets the threshold and corresponds to equality according to at least one of the frames. Distribution A involves equal amounts contributed, or 30 each for Low and High, and corresponds, therefore, to equality in the AC treatment frame. Distribution B states contributions of 20 for Low and 40 for High, which produces equal shares contributed and corresponds to equality in the RC frame. Since equal shares contributed is equivalent to equal shares kept, Distribution B also corresponds to equality in the RK frame. Finally, Distribution C corresponds to equality in the AK frame and involves equal amounts kept, i.e., 30 each for both Low and High or, in terms of the amounts contributed that are displayed in Table 2, 10 for Low and 50 for High. Of course, adjustments are made according to treatment in the wording (contributed/kept) and in the values of all three distributions (amounts/percentages).

Table 2: Standards of equality by frame

\begin{tabular}{|c|l|c|c|c|}
\cline { 3 - 5 } \multicolumn{2}{c|}{} & \multicolumn{3}{|c|}{ Amounts contributed by equality frame (NOK) } \\
\cline { 3 - 5 } \multicolumn{2}{c|}{} & $\begin{array}{c}\text { A } \\
\text { Equal amounts } \\
\text { contributed } \\
\text { (AC) }\end{array}$ & $\begin{array}{c}\text { B } \\
\text { Equal shares } \\
\text { contributed/kept } \\
\text { (RC, RK) }\end{array}$ & $\begin{array}{c}\text { C } \\
\text { Equal amounts } \\
\text { kept } \\
(\text { AK) }\end{array}$ \\
\hline \multirow{2}{*}{ Endowment } & High (NOK 80) & 30 & 40 & 50 \\
\cline { 2 - 5 } & Low (NOK 40) & 30 & 20 & 10 \\
\hline
\end{tabular}

The experiment was conducted at the Oeconlab at the University of Oslo with computers using Z-tree software (Fischbacher 2007). Subjects were recruited from the undergraduate population through a website and class announcements. There were twelve sessions, three for each of the four treatments, involving a total of 256 student subjects recruited from various colleges and majors at the University of Oslo. There were $20-28$ subjects in each session. All sessions were conducted February and March of 2010, except the RK sessions, which took place September 2015. With no show up fees, the earnings, which resulted from the four paid rounds, were all salient and averaged NOK 413 per subject, or about US\$ 60 , for sessions lasting about 90 minutes.

\section{Results and Analysis}

This section reviews and analyzes the results on the two types of proposals in this study, viz., the contributions, i.e., the binding and implemented proposals on subjects themselves, and 
the suggestions, i.e., the amounts subjects propose other members of their group contribute.

\subsection{Contributions}

The large majority of the 256 possible projects in all treatments was implemented (97\% overall), indeed, most succeeded in the first period. As can be seen from Table 3, however, the rate and speed of success differed across treatments. Whereas 93\% were implemented already in the first period the Relative Keep (RK) treatment, this drops significantly to $67 \%$ in Absolute Keep (AK) treatment $(\mathrm{p}<0.01) .^{12}$

\section{Table 3}

Project success rates

\begin{tabular}{|c|c|c|c|c|}
\hline \multirow[b]{2}{*}{ Period implemented } & \multicolumn{4}{|c|}{ Treatment (implementation percentage by period) } \\
\hline & $\mathrm{AC}$ & $\underline{\mathrm{RC}}$ & $\mathrm{AK}$ & $\underline{\mathrm{RK}}$ \\
\hline First period & $\overline{84}$ & $\overline{80}$ & $\overline{67}$ & $\overline{93}$ \\
\hline Second period & 9 & 9 & 15 & 2 \\
\hline Third period & 5 & 8 & 14 & 2 \\
\hline Failed & 2 & 3 & 4 & 3 \\
\hline Number of possible projects & 64 & 64 & 72 & 56 \\
\hline
\end{tabular}

Figures $1 \mathrm{~A}$ and 1B illustrate average contributions for payoff-relevant periods (i.e., the binding proposals for oneself in successful periods and in the last period of failed rounds). These are broken down by endowment, High (H) or Low (L), and treatment (AC, RC, AK and RK). The upper panels display the results in absolute terms as NOK, and the lower panels show the same values but expressed as percentages of endowments.

The differences in absolute contributions by endowment are striking: contributions from $\mathrm{H}$ subjects exceed those from $\mathrm{L}$ subjects by substantial amounts across all treatments. Average absolute contributions by $\mathrm{H}$ subjects are close to 50 in all cases; contributions by L subjects, however, are highest in the Absolute Contribute treatment and lowest in the two Keep treatments. Perhaps equally striking is the similarity of contributions in relative, or percentage, terms across both endowment groups and treatments. All groups contribute $60-70 \%$ of their endowments, except for the low endowed in the Absolute Contribute treatment, who stand out by contributing almost $80 \%$. In order to examine jointly the magnitude and significance of the effects of treatments and endowments, we turn now to regression analysis.

\footnotetext{
12 The difference between first period implementation of $80 \%$ in $\mathrm{RC}$ and $67 \%$ in $\mathrm{AK}$ is also significant ( $\mathrm{p}=0.05$ ). Other differences are not statistically significant.
} 
Table 4 presents the results of OLS regression analysis of contributions on all endowment and treatment variables in implemented periods clustered on group level. ${ }^{13}$ Consider first regressions 1 and 2, which take the Absolute Contribute treatment as the reference category, i.e.,

Figure 1: Mean contributions
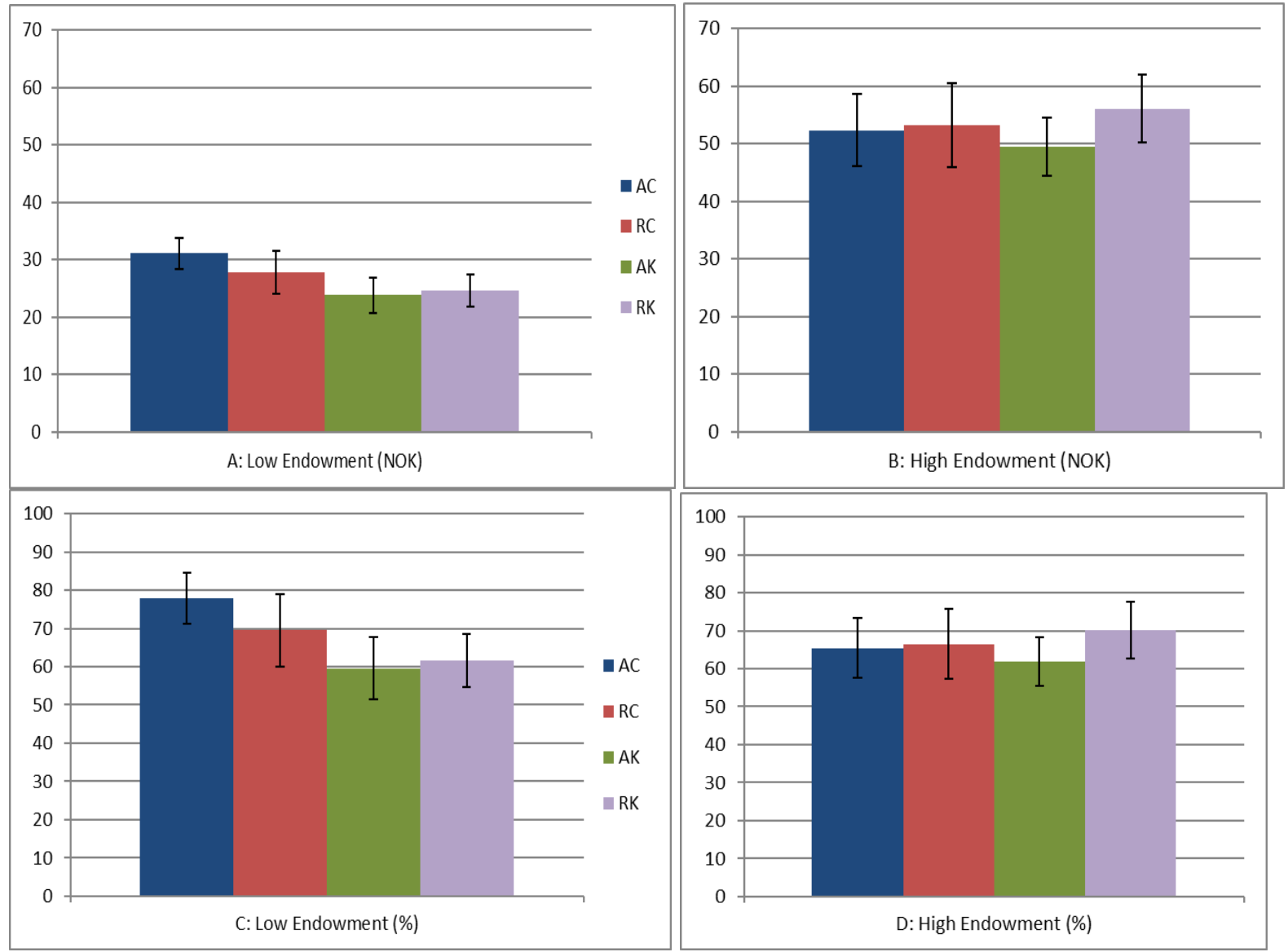

Notes: The upper panels (A, B) express contributions in absolute terms as NOK, and the lower panels (C, D) as percentages of endowments, both for payoff-relevant periods. The left panels refer to contributions of Low endowed subjects and the right panels to those of High endowed subjects. Error bars indicate 95\% confidence intervals.

the contributions of Low endowed in the AC treatment are captured by the constant, and contributions of High endowed in the AC treatment are reflected in "High." The use of treatment dummies for both $\mathrm{L}$ and $\mathrm{H}$ means that the interaction term coefficients measure the treatment effect separately for each endowment group. The dependent variable in regression 1 is absolute

\footnotetext{
${ }^{13} \mathrm{We}$ also ran the regressions for this table while controlling for subject expenditures, parents' income and gender. None of the control variables is significant, and the other coefficients are similar to those in Table 4, so we have relegated these regressions to Appendix B, Table A1. Two observations are missing from the second session of the Relative Contribute treatment in this analysis because of a computer glitch during the experiment.
} 
contributions in NOK and in regression 2 it is relative contributions (i.e., as percentage of respective endowments). Given the frequently observed pattern of declining average contributions over time in multi-round public good experiments, we also include a variable for Round (with the first paid round coded as zero). This reveals a significant decrease in contributions over time: regression 1 indicates an absolute magnitude of about NOK 1 per round.

From regression 1 , we see that the $\mathrm{H}$ subjects always contribute significantly more in absolute terms than L subjects; indeed, $\mathrm{H}$ contributions are consistently high across treatments.

Table 4: OLS regressions of contributions

\begin{tabular}{|c|c|c|c|c|}
\hline & $\begin{array}{c}\text { (1) } \\
\text { Absolute contr. }\end{array}$ & $\begin{array}{c}\text { (2) } \\
\text { Relative contr. }\end{array}$ & $\begin{array}{c}\text { (3) } \\
\text { Absolute contr. }\end{array}$ & $\begin{array}{c}\text { (4) } \\
\text { Relative contr. }\end{array}$ \\
\hline Constant & $\begin{array}{l}32.80^{* * *} \\
(1.46)\end{array}$ & $\begin{array}{l}0.80^{* * *} \\
(0.04)\end{array}$ & $\begin{array}{l}25.50^{* * * *} \\
(1.82)\end{array}$ & $\begin{array}{l}0.62^{* * *} \\
(0.04)\end{array}$ \\
\hline LxAC & & & $\begin{array}{l}7.30^{* * *} \\
(2.13)\end{array}$ & $\begin{array}{l}0.18^{* * *} \\
(0.05)\end{array}$ \\
\hline LxRC & $\begin{array}{l}-3.34 \\
(2.34)\end{array}$ & $\begin{array}{l}-0.08 \\
(0.06)\end{array}$ & $\begin{array}{l}3.96 \\
(2.52)\end{array}$ & $\begin{array}{c}0.10 \\
(0.06)\end{array}$ \\
\hline LxAK & $\begin{array}{l}-7.30^{* * *} \\
(2.13)\end{array}$ & $\begin{array}{l}-0.18^{* * *} \\
(0.05)\end{array}$ & & \\
\hline LxRK & $\begin{array}{l}-6.51^{* * *} \\
(1.95)\end{array}$ & $\begin{array}{l}-0.16^{* * *} \\
(0.05)\end{array}$ & $\begin{array}{l}0.80 \\
(2.16)\end{array}$ & $\begin{array}{c}0.02 \\
(0.05)\end{array}$ \\
\hline High & $\begin{array}{l}21.16^{* * *} \\
(3.40)\end{array}$ & $\begin{array}{l}-0.13^{* *} \\
(0.05)\end{array}$ & $\begin{array}{l}25.65^{* * *} \\
(3.43)\end{array}$ & $\begin{array}{l}0.02 \\
(0.06)\end{array}$ \\
\hline $\mathrm{HxAC}$ & & & $\begin{array}{c}2.81 \\
(4.17)\end{array}$ & $\begin{array}{c}0.04 \\
(0.05)\end{array}$ \\
\hline HxRC & $\begin{array}{c}0.90 \\
(4.94)\end{array}$ & $\begin{array}{c}0.01 \\
(0.06)\end{array}$ & $\begin{array}{c}3.72 \\
(4.58)\end{array}$ & $\begin{array}{c}0.05 \\
(0.06)\end{array}$ \\
\hline HxAK & $\begin{array}{l}-2.81 \\
(4.17)\end{array}$ & $\begin{array}{l}-0.04 \\
(0.05)\end{array}$ & & \\
\hline HxRK & $\begin{array}{c}3.81 \\
(4.43)\end{array}$ & $\begin{array}{c}0.05 \\
(0.06)\end{array}$ & $\begin{array}{c}6.62 \\
(4.03)\end{array}$ & $\begin{array}{c}0.08 \\
(0.05)\end{array}$ \\
\hline Round & $\begin{array}{l}-1.10^{* * *} \\
(0.38)\end{array}$ & $\begin{array}{l}-0.02^{* *} \\
(0.01)\end{array}$ & $\begin{array}{l}-1.10^{* * *} \\
(0.38)\end{array}$ & $\begin{array}{l}-0.02^{* *} \\
(0.01)\end{array}$ \\
\hline$N$ & 1022 & 1022 & 1022 & 1022 \\
\hline
\end{tabular}


adj. $R^{2}$

0.39

0.04

0.39

0.04

Notes: The dependent variable in regressions 1 and 3 is absolute contributions in NOK and in regressions 2 and 4 relative contributions (i.e., percentages of respective endowments). The reference category in regressions 1 and 2 is Absolute Contribute and in 3 and 4 Absolute Keep. Only payoff relevant periods are included, standard errors appear in parentheses, and statistical significance is indicated as ${ }^{*} p<0.1,{ }^{* *} p<0.05,{ }^{* * *} p<0.01$. Standard errors are clustered on group and are, therefore, robust. All parameters retain the same signs and levels of significance after a Bonferroni correction for the simultaneous testing of nine parameters, except Round, which drops one level in significance in all columns. Due to a technical glitch during the experiment, two observations from the RC treatment are not included.

The interaction terms suggest that framing affects L subjects but not $\mathrm{H}$ subjects. Specifically, contributions of L subjects in the Absolute Contribute treatment equal about NOK 33 and differ significantly from zero ( $\mathrm{L}$ being the omitted category). The results in this table are robust to Bonferroni (1935) correction for multiple hypothesis testing. In Table 4, this involves the simultaneous test of all nine parameters, including round and the constant. ${ }^{14}$

The insignificance of RC and significance and similar magnitude of AK and RK for $\mathrm{L}$ subjects seem to suggest that the Keep frame reduces L contributions compared with Contribute, but that the metric frame (i.e., Absolute/Relative) matters less or not at all. Regression 2, where the dependent variable is percentage of respective endowment, confirms this pattern: $\mathrm{L}$ subjects in the AC treatment contribute more than any other group, about $80 \%$ of their endowment, which is a significantly higher share than $\mathrm{L}$ subjects in the $\mathrm{AK}$ and $\mathrm{AR}$ treatments and also a significantly higher share than $\mathrm{H}$ subjects. The results are similar, if we collapse payoff relevant individual contributions and employ a non-parametric Wilcoxon rank-sum test: for low endowed $\mathrm{AC}$ is significantly different from both $\mathrm{AK}(\mathrm{p}<0.01)$ and $\mathrm{RK}(\mathrm{p}<0.01) .{ }^{15}$

These results suggest that the AC treatment might be distinctive, so we tried specifications that omit AK instead of AC. Regressions 3 and 4 correspond to 1 and 2, respectively, except for this change of reference category. Regression 3 confirms the suspicion: Contributions by $\mathrm{L}$ in $\mathrm{AK}$ of 25.5 differ significantly from zero, and $\mathrm{H}$ contributions in this treatment are almost exactly double this amount. The only significant treatment effect, however, is for $\mathrm{L}$ subjects in the AC treatment: they contribute about 7.3 NOK more than L subjects in AK. Regression 4 reveals that the mean contribution is $62 \%$, with no significant differences in

\footnotetext{
${ }^{14}$ In general, the Bonferroni correction involves the following. With $m$ hypotheses, if we reject individual hypotheses at significance level $\alpha$, the probability of rejecting at least one will be higher than $\alpha$ and closer to $m \alpha$. Bonferroni showed that if we rejected individual hypotheses at the level $\alpha / m$, the probability of falsely rejecting any of the $m$ hypothesis is less than $\alpha$.

${ }^{15}$ For high endowed, the difference between AK and $\mathrm{RK}$ is significant $(\mathrm{p}=0.03)$; otherwise no other difference is significant.
} 
relative contributions by endowment or treatment, save one: Low subjects in the Absolute Contribute treatment contribute about $80 \%$, or 18 percentage points more than the reference group. Based on this finding, we use $\mathrm{AK}$ as the reference category in the further analysis.

Contributions are constrained in our experiment: remember L subjects can contribute between NOK 0 and 40 and $\mathrm{H}$ between NOK 0 and 80. To address possible censoring of data, therefore, we also report the results of Tobit regressions in Table 5. ${ }^{16}$ The dependent variable is absolute contributions in NOK, and there are separate regressions for $\mathrm{L}$ and $\mathrm{H}$, since these groups have different censor points. OLS regressions appear in columns 1 and 2 , and the corresponding Tobit regressions appear in columns 3 and 4, respectively.

Table 5: OLS and Tobit regression analysis of contributions by endowment

\begin{tabular}{|c|c|c|c|c|}
\hline & \multicolumn{2}{|c|}{ OLS } & \multicolumn{2}{|c|}{ Tobit } \\
\hline & $(1)$ & $(2)$ & (3) & $(4)$ \\
\hline & Low & High & Low & High \\
\hline Constant (AK) & $\begin{array}{l}24.52^{* * *} \\
(1.74)\end{array}$ & $\begin{array}{l}52.13^{* * *} \\
(2.85)\end{array}$ & $\begin{array}{l}26.76^{* * * *} \\
(2.65)\end{array}$ & $\begin{array}{l}54.46^{* * *} \\
(3.52)\end{array}$ \\
\hline Absolute cont. & $\begin{array}{l}7.30^{* * *} \\
(2.13)\end{array}$ & $\begin{array}{c}2.81 \\
(4.17)\end{array}$ & $\begin{array}{l}12.96^{* * *} \\
(3.76)\end{array}$ & $\begin{array}{l}4.58 \\
(5.29)\end{array}$ \\
\hline Relative contr. & $\begin{array}{c}3.95 \\
(2.52)\end{array}$ & $\begin{array}{c}3.71 \\
(4.58)\end{array}$ & $\begin{array}{l}6.78 \\
(4.18)\end{array}$ & $\begin{array}{l}5.57 \\
(5.98)\end{array}$ \\
\hline Relative Keep & $\begin{array}{c}0.80 \\
(2.16)\end{array}$ & $\begin{array}{l}6.62 \\
(4.03)\end{array}$ & $\begin{array}{c}0.56 \\
(3.18)\end{array}$ & $\begin{array}{c}8.56 \\
(5.21)\end{array}$ \\
\hline Round & $\begin{array}{l}-0.45 \\
(0.39)\end{array}$ & $\begin{array}{l}-1.75^{\text {*** }} \\
(0.62)\end{array}$ & $\begin{array}{l}-0.67 \\
(0.66)\end{array}$ & $\begin{array}{l}-2.28^{* * *} \\
(0.83)\end{array}$ \\
\hline
\end{tabular}

\begin{tabular}{lllll}
\hline$N$ & 511 & 511 & 511 & 511 \\
adj. $R^{2}$ & 0.05 & 0.02 & & \\
\hline
\end{tabular}

Notes: The dependent variable is absolute contributions (NOK) with separate regressions for $\mathrm{L}$ and $\mathrm{H}$ subjects. Regressions 1 and 2 are OLS and 3 and 4 are Tobit. Only payoff relevant periods are included. Standard errors, which are clustered on group, appear in parentheses, whereby ${ }^{*} p<0.1,{ }^{* *} p<0.05,{ }^{* * *} p<0.01$.

Qualitatively, the Tobit regressions corroborate the main findings from the previous OLS

\footnotetext{
${ }^{16}$ We thank a referee of this journal for prompting us to conduct these tests.
} 
analysis: $\mathrm{H}$ subjects contribute more than L, and framing affects only L subjects; specifically, the AC frame stands out. Overall, though, comparison of the Tobit and OLS regressions suggest the constraints did affect contributions quantitatively, mostly on the upper end of the permissible range. Comparing regressions 1 and 3 , we see that the framing effect is quantitatively larger in the latter: the coefficient on AC is around NOK 13 in the Tobit regression, compared with about NOK 7 in the OLS analysis. Thus, the estimated contribution of L in the AC treatment is almost NOK 40, which is also consistent with the fact that the median contribution of these subjects is NOK 40. This contrasts with all other treatments, for which the median contributions are at least $25 \%$ below the maximum.

The separation of the analysis into $\mathrm{L}$ and $\mathrm{H}$ also uncovers a new finding: the depressing effect of rounds on contributions is only significant for $\mathrm{H}$ subjects, whose contributions fall about 2 NOK per round as opposed to the 1 NOK estimate in Table 4, largely because the constraint is binding on fewer of the more generous $\mathrm{H}$ subjects than the more generous $\mathrm{L}$ subjects.

\subsection{Suggestions}

Recall that subjects made two types of proposals every period: binding "contributions" for themselves and non-binding "suggestions" for others. The suggestions of all subjects were communicated to all other group members prior to the subsequent period.

Table 6. Tobit regressions of suggestions

(1) Sugg. for Low

\begin{tabular}{lcccc}
\hline & & & \\
Constant & $25.88^{* * *}$ & $(2.22)$ & $56.34^{* * *}$ & $(3.78)$ \\
LxAC & $12.95^{* * *}$ & $(3.70)$ & $16.19^{* *}$ & $(6.41)$ \\
LxRC & $7.45^{* *}$ & $(3.31)$ & $12.47^{* *}$ & $(5.09)$ \\
LxAK & & & $8.99^{* *}$ & $(4.50)$ \\
LxRK & 0.71 & $(3.02)$ & 2.23 & $(5.54)$ \\
HxAC & $10.20^{* * *}$ & $(3.03)$ & 5.63 & $(5.86)$ \\
HxRC & $8.24^{* *}$ & $(3.60)$ & 5.20 & $(6.01)$ \\
HxAK & 1.63 & $(1.55)$ & & \\
HxRK & 3.72 & $(2.95)$ & 5.84 & $(5.92)$ \\
round & $1.21^{* * *}$ & $(0.44)$ & $1.77^{* *}$ & $(0.71)$ \\
\hline \multicolumn{5}{c}{} \\
\end{tabular}
(2)
Sugg. for High

1024 
Note: The dependent variable is suggestions for low endowed in Column (1) and suggestions for high endowed in Column (2), measured in absolute terms (NOK). Variable names in lines indicate whether suggestions were made by high $(\mathrm{H})$ or low $(\mathrm{L})$ endowed. Only payoff relevant periods are included, standard errors appear in parentheses, and statistical significance is indicated as ${ }^{*} p<0.1,{ }^{* *} p<0.05,{ }^{* * *} p<0.01$. Standard errors are clustered on group. In both columns the omitted variable is the suggestions from the same type in treatment AK.

Interestingly, the overall pattern of suggestions looks quite similar to what we observe for contributions. Table 6 presents Tobit regressions of suggestions for others. Beginning in column (1) with suggestions to low endowed, there is again a treatment effect in AC: compared to the AK treatment, both $\mathrm{H}$ and $\mathrm{L}$ suggest substantially higher contributions for the low endowed in the $\mathrm{AC}$ frame that remain significant at the $1 \%$ level after Bonferroni corrections. The other coefficients in this column, by contrast, do not remain significant after this correction. Regarding suggestions to the high endowed, column (2) indicates that low endowed subjects suggest higher amounts for these subjects than the high endowed do, except in the RK treatment. Nevertheless, these are not significant at conventional levels after correcting for multiple hypothesis testing.

A possible explanation for the similar patterns of contributions and suggestions is that subjects are influenced by others' suggestions when deciding how much to contribute. This does not appear to be the case, however, according to further regressions reported in Appendix B (see Table A2). We are unable to identify statistically significant impacts on contributions of others' lagged suggestions or lagged contributions. Subjects simply do not seem to be swayed by others' suggestions. An alternate explanation for the similar patterns is that certain frames, the Absolute Contribution frame in particular, induce people to expect more of the Low endowed.

Finally and perhaps not surprisingly, subjects tend to suggest greater sacrifice from their same endowment counterparts than they propose for themselves based on results reported in Table A3 of Appendix B: H suggest higher contributions from other $\mathrm{H}$ than they contribute themselves, and analogously for L subjects. As discussed above, however, these inflated suggestions seem to be received as cheap talk that does not matter for behavior.

\subsection{Motives}

Given the evidence above that contributions vary in certain ways with endowment size and framing, we examine whether distributive preferences play a role in this. In the absence of any known differences between subjects other than endowment heterogeneity, subjects might consider as 'fair' an equal sharing of the burden required to reach the threshold. With endowment heterogeneity, however, the question is "equality in what?" 
Table 2 in section 2 presented three possible ways to share the burden of meeting the threshold: equal absolute contributions (A); equal relative contributions (B), corresponding also to equal relative amounts kept; and equal absolute amounts kept (C). It might be the case that subjects are more likely to consider as 'fair' the rule that achieves equality in the contribution metric used in their treatment and that such fairness views influence actual contributions. If so, we would expect to see contributions from the low endowed declining from $\mathrm{AC}$ to $\mathrm{RC} / \mathrm{RK}$ to $\mathrm{AK}$, and contributions from high endowed increasing in the same order. Nevertheless, support for this idea in the data turns out to be weak at best.

First, as reported above, we do find that L contribute more in $\mathrm{AC}$ than in $\mathrm{AK}$, consistent with the hypothesis. Also, suggestions for L are higher in RC than in AK, and still higher in AC. Nevertheless, there is no significant difference between AK and RK for Low endowed (either for contributions or for suggestions), and there are no treatment effects for the high endowed, whatsoever.

Table 7. Regression analysis of fairness question and contributions

\begin{tabular}{|c|c|c|c|c|c|}
\hline & $\begin{array}{l}\text { (1) } \\
\text { Fair contr. for } \\
\text { self, Low }\end{array}$ & $\begin{array}{c}\text { (2) } \\
\text { Fair contr. for } \\
\text { self, High }\end{array}$ & $\begin{array}{c}(3) \\
\text { Share } \\
\text { choosing C as } \\
\text { fairest }\end{array}$ & $\begin{array}{c}(4) \\
\text { Contribution, } \\
\text { Low }\end{array}$ & $\begin{array}{c}(5) \\
\text { Contribution, } \\
\text { High }\end{array}$ \\
\hline Constant & $\begin{array}{l}16.67^{* * *} \\
(1.12)\end{array}$ & $\begin{array}{l}43.06^{* * * *} \\
(0.90)\end{array}$ & $\begin{array}{l}0.40^{* * * *} \\
(0.07)\end{array}$ & $\begin{array}{l}21.48^{* * *} \\
(4.27)\end{array}$ & $\begin{array}{l}38.23^{* * * *} \\
(12.62)\end{array}$ \\
\hline $\mathrm{AC}$ & $\begin{array}{l}1.458 \\
(1.28)\end{array}$ & $\begin{array}{l}-1.81 \\
(1.30)\end{array}$ & $\begin{array}{c}-0.18^{\text {** }} \\
(0.08)\end{array}$ & $\begin{array}{l}12.44^{* * * *} \\
(3.71)\end{array}$ & $\begin{array}{c}5.29 \\
(5.31)\end{array}$ \\
\hline $\mathrm{RC}$ & $\begin{array}{l}-0.42 \\
(1.72)\end{array}$ & $\begin{array}{c}0.38 \\
(1.32)\end{array}$ & $\begin{array}{c}0.07 \\
(0.10)\end{array}$ & $\begin{array}{c}6.95^{*} \\
(4.04)\end{array}$ & $\begin{array}{c}5.45 \\
(6.03)\end{array}$ \\
\hline RK & $\begin{array}{c}0.12 \\
(1.48)\end{array}$ & $\begin{array}{c}-0.56 \\
(1.90)\end{array}$ & $\begin{array}{c}0.04 \\
(0.10)\end{array}$ & $\begin{array}{c}0.54 \\
(3.14)\end{array}$ & $\begin{array}{c}8.81^{*} \\
(5.23)\end{array}$ \\
\hline Round & & & & $\begin{array}{l}-0.67 \\
(0.65)\end{array}$ & $\begin{array}{l}-2.29^{* * * *} \\
(0.83)\end{array}$ \\
\hline $\begin{array}{l}\text { Fair contr. } \\
\text { for self }\end{array}$ & & & & $\begin{array}{c}0.32 \\
(0.21)\end{array}$ & $\begin{array}{c}0.38 \\
(0.25)\end{array}$ \\
\hline $\begin{array}{l}N \\
\text { adj. } R^{2}\end{array}$ & 128 & 128 & $\begin{array}{c}256 \\
0.029\end{array}$ & 511 & 511 \\
\hline
\end{tabular}


Notes: Fair contr. for self is defined as the contribution for the subject herself implied by her answer to the question "Which of the following sets of decisions do you think is most fair?", whereby the response alternatives are indicated in Table 2. This is the dependent variable in Column (1) and (2). In Column (3), the dependent variable is the share of subjects who choose $\mathrm{C}$ (equal amounts kept in Table 2) as the fairest alternative. All columns report Tobit regressions, except Column (3), which is standard OLS since censoring is not an issue. In Columns (4) and (5), the dependent variable is absolute contributions (NOK). Only payoff relevant periods are included, and standard errors, which are clustered on group, appear in parentheses. Levels of significance are denoted ${ }^{*} p<0.1,{ }^{* *} p<0.05$, ${ }^{* * *} p<0.01$. The omitted category is AK.

Second, we do not observe strong treatment effects on reported fairness views. In the post-experimental questionnaire, subjects were asked which of three sets of contributions presented in Table 2 they considered fairest. In responding to this question, each subject implicitly chose the fairest contribution for herself (among the three alternatives offered). Table 7 examines whether the elicited fairness preferences are affected by frames, and if so, whether this can explain treatment effects on actual contributions. While we do see indications of some treatment effects on fairness views, the effects are weak at best; furthermore, fairness views cannot explain the observed treatment effect on contributions.

In Table 7, the variable "Fair contribution for self" is the hypothetical contribution for the subject herself implied by her choice of fairness principle (see Table 2). As can be seen from columns (1) and (2), there are no treatment effects on subjects' choice of the fairest contribution for themselves. Several alternative modelling approaches did not affect this result, except for one: as reported in Column (3), the share of subjects choosing equal amounts kept (C) as the fairest alternative is significantly lower in AC. ${ }^{17}$ Although consistent with the hypothesis discussed above, this finding does not remain statistically significant after correcting for multiple hypotheses.

Given that the treatment effects on fairness views are weak at best, they can hardly explain the observed treatment effect on L's contributions in AC (which does survive a Bonferroni correction). This is confirmed by Column (4) and (5) of Table 7, which report OLS regressions of contributions: although the coefficients for the fairest contribution for oneself are positive for $\mathrm{H}$ as well as $\mathrm{L}$ subjects, they are not significant. Moreover, the inclusion of this variable does not remove the positive and statistically significant treatment effect of the AC treatment on Low's contributions, which changes little in magnitude.

Recall that the post-experimental questionnaire included two additional questions about

\footnotetext{
${ }^{17}$ Overall, $90 \%$ of subjects choose either B or C as the fairest alternative. In the AC treatment, $22 \%$ choose C, whereas the average share choosing $\mathrm{C}$ in the three other treatments was $44 \%$.
} 
broader distributive preferences: what contributions subjects would have chosen, if they could have made them binding on all (Dictate), and what they thought each member should have contributed (Should). We consider now, therefore, regression analysis that includes responses to all three questions on distributive preferences. We return to OLS regressions in order to be able to examine simultaneously effects of distributive preferences not only by treatment but also by endowment (a comparison not possible with Tobit given the different censor points for $\mathrm{H}$ and $\mathrm{L}$ ). In Table 8, regression (2) includes responses to the three questions on distributive preferences with respect to one's own allocation, whereas (1) duplicates the results from regression (3) of Table 4 without these questions for comparison.

A comparison of the coefficients of determination for (1) and (2) indicates distributive preferences account for a substantial fraction of variance in contributions. Indeed, the Dictate and Should questions are significant at the one percent level, whereas Fair is marginally significant. ${ }^{18}$ Nevertheless, these questions do not explain contributions: Low in the AC treatment remains significant, although only weakly so after a Bonferroni correction, whereas no other treatment effect is even marginally significant after Bonferroni corrections. On the other hand, the larger contributions by $\mathrm{H}$ subjects are explained by distributive preferences: the coefficient on High falls from 25.65, which is significant at the $1 \%$ level, to only 6.46 , which is not even marginally significant after a Bonferroni correction. Thus, distributive preferences offer an explanation for the robust finding that high endowed subjects contribute more than low endowed subjects across all frames. On the other hand, there is little indication that the observed treatment effect on contributions can be explained by a framing effect on subjects' preferences.

Table 8. OLS regressions of contributions including distributive preferences.

\begin{tabular}{lllll}
\hline & \multicolumn{3}{c}{$(1)$} & \multicolumn{3}{c}{$(2)$} \\
\hline Constant & $25.50^{* * * *}$ & $(1.82)$ & $9.51^{* * *}$ & $(2.75)$ \\
LxAC & $7.30^{* * *}$ & $(2.13)$ & $4.77^{* *}$ & $(2.08)$ \\
LxRC & 3.96 & $(2.52)$ & $4.59^{*}$ & $(2.38)$ \\
LxRK & 0.80 & $(2.16)$ & $-3.49^{*}$ & $(2.03)$ \\
High & $25.65^{* * *}$ & $(3.43)$ & $6.46^{*}$ & $(3.73)$ \\
HxAC & 2.81 & $(4.17)$ & 0.10 & $(2.74)$
\end{tabular}

\footnotetext{
${ }^{18}$ Since we test the effect of all three fairness variables here, we also adjust for three hypotheses in a Bonferroni correction, but the conclusions about sign and significance remain unchanged.
} 


\begin{tabular}{lllll} 
HxRC & 3.72 & $(4.58)$ & 0.66 & $(3.07)$ \\
HxRK & 6.62 & $(4.03)$ & 1.59 & $(2.81)$ \\
Round & $-1.10^{* * *}$ & $(0.38)$ & $-1.10^{* * *}$ & $(0.38)$ \\
Fair & & $0.17^{*}$ & $(0.09)$ \\
Dictate & & $0.13^{* * *}$ & $(0.05)$ \\
Should & & $0.40^{* * *}$ & $(0.06)$ \\
\hline$N$ & & & 1022 \\
adj. $R^{2}$ & 1022 & & 0.53 \\
\hline
\end{tabular}

Notes: The dependent variable is absolute contributions (NOK), the reference category is Low/AK, and only payoff relevant periods are used. Standard errors appear in parentheses, are clustered on group, and statistical significance is indicated as ${ }^{*} p<0.1,{ }^{* *} p<0.05,{ }^{* * *} p<0.01$. Due to a technical error during the experiment, two observations from the RC treatment are missing. Fair, Dictate and Should are all responses that refer to the subject's own contributions.

\section{Conclusions}

The results of our threshold public good game with heterogeneous endowments show a clear effect of endowment size on contributions and suggest this is due to distributive preferences. On the other hand, they provide more limited evidence of metric and choice framing on contributions. The treatment that stands out in our experiment is the one framing the contribution metric in terms of absolute amounts contributed, instead of alternative, economically equivalent frames: amounts relative to endowment, absolute amounts kept, or amounts kept relative to endowments. In particular, when the contribution metric is framed in terms of absolute amounts contributed, the low endowed contribute significantly more than with other frames.

One explanation for the observed treatment effects might be that the frame influences morally motivated subjects' beliefs about what is fair or ethically right, and that this in turn affects their behavior. Our data, however, provide no convincing support for this hypothesis. Treatment effects on subjects' reported fairness preferences are not strong, and the weak treatment effects that are present cannot explain the effects we do observe on actual behavior. Since there are multiple equilibria in the game, however, different frames might also suggest different anchoring or focal points, thereby influencing subjects' expectations of others' behavior - which could affect self-interested subjects as well as those with social preferences.

Distributive preferences do not explain the treatment effect on contributions, but it is conceivable that equal sharing serves as a focal point for coordination, specifically, that the 
treatment affects the most natural equality principle and, thereby, the focal point. One can only conjecture, however, about why only the low endowed are affected. The contributions implied by the three equality principles shown in Table 2 differ more in relative terms for the low endowed, conceivably triggering a stronger psychological response for these subjects; however, at this point we are left to mere speculation.

Finally, treatment effects could conceivably be due to calculation errors if, for example, subjects think in relative terms and make systematic errors when converting absolute values into percentages. It seems unlikely, however, that this can fully explain our finding that low endowed subjects contribute more with the Absolute Contribution frame. In the AC treatment, the median contribution for Low endowed is $40 \mathrm{NOK}$, corresponding to these subjects' entire endowment. The alternative of giving everything is easily calculated in all frames.

If contributions are affected by framing, this could have implications outside the laboratory, as well. Situations in the field that share important features of our experiment include labor negotiations, distribution of household chores, and international environmental treaties. In such cases, framing contributions in absolute or relative terms, and in terms of contributing or keeping, might influence beliefs, negotiations' success rates, and the ultimate sharing of burdens. Further research is, therefore, needed to explore the robustness and external validity of our main findings.

\section{REFERENCES}

Andreoni, J. (1995). "Warm-Glow Versus Cold-Prickle: The Effects of Positive and Negative Framing on Cooperation in Experiments." The Quarterly Journal of Economics, vol. 110, no. 1 (February), pp. 121.

Balafoutas, L., Kocher, M., Putterman, L., and Sutter, M.,(2010). "Equality, Equity and Incentives: An Experiment." IZA Discussion Paper 5204 (September).

Bernard, M., E. Reuben, and A. Riedl (2013): Fairness and Coordination: The Role of Fairness Principles in Coordination Failure and Success. Mimeo.

Bochet, O. and Putterman, L., 2009. "Not just babble: Opening the black box of communication in a voluntary contribution experiment," European Economic Review, vol. 53(3), 309-326.

Bonferroni, C. E., (1935). "Il calcolo delle assicurazioni su gruppi di teste.” Tipografia del Senato.

Buckley, E., and Croson, R. (2006). "Income and Wealth Heterogeneity in the Voluntary Provision of Linear Public Goods.” Journal of Public Economics 90, 935-955.

Cappelen, A.W, J. Konow, E.Ø. Sørensen and B. Tungodden, 2013. "Just Luck: An Experimental Study of Risk-Taking and Fairness," American Economic Review 103(4), 1398-1413. 
Cookson, Richard (2000). "Framing Effects in Public Goods Experiments." Experimental Economics, vol. 3, no. 1 (June), pp. 55-79.

Chaudhuri, A. (2011). "Sustaining Cooperation in Laboratory Public Goods Experiments: A Selective Survey of the Literature.” Experimental Economics, vol. 14, no. 1 (March), pp. 47-83.

Cherry, T. L., Kroll, S. and Shogren, J. F., (2005). "The Impact of Endowment Heterogeneity and Origin on Public Good Contributions: Evidence from the Lab." Journal of Economic Behavior \& Organization, vol. 57, no. 3 (July), pp. 357-365.

Croson, R. T. A. and Marks M.B., (2000): Step Returns in Threshold Public Goods: A Meta- and Experimental Analysis, Experimental Economics (2), 239-259.

Dawes, R., McTavish, J., and Shaklee H. (1977). "Behavior, Communication, and Assumptions about Other People's Behavior in a Commons Dilemma Situation," J. Personality and Social Psychology 35, $1-11$.

van Dijk, F., Sonnemans, J., and van Winden, F. (2002). "Social Ties in a Public Good Experiment." Journal of Public Economics, vol. 85, no. 2 (August), pp. 275-299.

Durante, R. Putterman, L., van der Weele, J. (2014). "Preferences for Redistribution and Perception of Fairness: An Experimental Study.” Journal of European Economic Association, vol. 12, no. 4 (August), pp. 1059-1086.

Fischbacher, U. (2007). z-Tree: Zurich toolbox for ready-made economic experiments, Experimental Economics 10(2), 171-178.

Fischbacher, U., Güth, W., and Levati, M. V., (2011). "Crossing the Point of No Return: A Public Goods Experiment.” Jena Economic Research Paper 2011-059.

Hofmeyr, A., Burns, J. and Visser, M. (2007). "Income Inequality, Reciprocity and Public Good Provision: An Experimental Analysis.” South African Journal of Economics, vol. 75, no. 3, pp. 508520.

Isaac, R. M., Schmidtz D. and Walker J.M. (1989): The assurance problem in a laboratory market, Public Choice 62(3), 217-236.

Johansson-Stenman, O., and Konow, J. (2010). "Fair Air: Distributive Justice and Environmental Economics," Environmental and Resource Economics, vol. 46, no. 2 (June), pp. 147-166.

Jacobsen, K.J., Eika, K.H., Helland, L., Lind, J.T., Nyborg, K. (2011): Are nurses more altruistic an real estate brokers? Journal of Economic Psychology 32, 818-831.

Khadjavi, M., and Lange A.,(2015): Experimental Evidence on Giving and Taking in Public Good Games, Experimental Economics 18: 432-441.

Lange, A., Loschel, A., Vogt, C. and Ziegler, A., (2010). "On the Self-interested use of Equity in International Climate Negotiations.” European Economic Review, Vol. 54, pp. 359-375.

Ledyard, J.O. (1995): "Public goods: a survey of experimental research", in John H. Kagel, Alvin E. Roth (Eds.), The Handbook of Experimental Economics, Princeton, New Jersey: Princeton University Press, 111-194.

McBride, M. (2010). "Threshold Uncertainty in Discrete Public Good Games: An Experimental Study." Economics of Governance, vol. 11, no. 1 (February), pp. 77-99.

Messer, K. D., Zarghamee, H., Kaiser, H. M. and Schulze, W. D., (2007). "New Hope for the Voluntary Contributions Mechanism: The effects of context." Journal of Public Economics, vol. 91, no. 9 (September), pp. 1783-1799. 
Milinski, M., Röhl, T., and Marotzke, J. (2011). "Cooperative Interaction of Rich and Poor Can Be Catalyzed by Intermediate Climate Targets." Climatic Change, vol. 109, Nos. 3-4, pp. 807-814.

Noussair, C., and Tan, F., (2011). "Voting on Punishment Systems within a Heterogeneous Group," Journal of Public Economic Theory, vol. 13, no. 5 (October), pp. 661-693.

Rapoport, A. and Suleiman, R., (1993). "Incremental Contribution in Step-level Public Goods Games with Asymmetric Players." Organizational Behavior and Human Decision Processes 55, pp. 171194.

Rege, M. and Telle, K., (2004). "The Impact of Social Approval and Framing on Cooperation in Public Good Situations.” Journal of Public Economics, vol. 88, pp. 1625-1644.

Reuben, E. and Riedl, A. (2013). "Enforcement of Contribution Norms in Public Good Games with Heterogeneous Populations." Games and Economic Behavior, vol. 77, no. 1, pp. 122-137.

Schelling, T.C. (1960): The Strategy of Conflict. Cambridge, MA: Harvard University Press.

Tavoni, A., Dannenberg, A., and Löschel, A., (2011): "Inequality, Communication, and the Avoidance of Disastrous Climate Change in a Public Goods Game." Proceedings of the National Academy of Science, vol. 108, no.29, 11825-11829. 


\title{
FOR ONLINE PUBLICATION \\ APPENDIX A
}

\author{
General Instructions
}

\section{Introduction}

This is an experiment in decision-making, in which you can earn money. The amount you earn will depend on your decisions and the decisions of others. This money has been provided by a research organization.

Please note that your participation is voluntary. You have the right to withdraw at any time and lose all payments you have received and will receive from your participation.

\section{Rules of Conduct}

The results from this experiment will be used in a research project. It is therefore very important that everyone who participates in the experiment follows certain rules of conduct. All mobile phones must be turned off, and you are not permitted to access any internet sites other than the one for this experiment. You are not allowed to talk with any of the other participants during the experiment. If you have questions or need help with the computer, please raise your hand and one of us will approach you and assist you privately.

\section{Payments and Anonymity}

All interaction between the participants will take place via computers. At the end of this experimental session, you will be provided with a code, which will be used by the accounting department to transfer your earnings from the session to your bank account. These procedures will also guarantee that your decisions and payments remain anonymous. That is, neither the researchers nor the other participants will know who made which decisions during the session.

\section{Groups}

In this experiment you will be randomly assigned to a group of four people. Each group of four will remain together throughout the experiment. You will not know who is in your group, nor will the other members of the group know who you are. Each participant will be known only as member 1, 2, 3 or 4.

\section{Rounds}

The experiment will consist of five rounds. The first round is a practice round to familiarize you with the rules. You will not earn money from this practice round. Then there will be four more rounds, and in each of these four rounds you will earn money. How much depends on the choices you and the others in your group make.

\section{Endowments}

At the beginning of each round, each of you will receive a sum of money, which we will call your "endowment." Members 1 and 2 in each group will receive 40 NOK in each round, and members 3 and 4 will receive $80 \mathrm{NOK}$ in each round. Member numbers, and therefore endowments, will be randomly 
assigned by the computer. Your member number, and thus the size of your endowment, will be the same in every round.

Your member number and endowment will now be drawn and presented on your screen. Please do not press the "continue" button until you are told to do so.

\section{Decision}

In each round, you may choose to keep your endowment or to contribute some or all of it to a group project. You may contribute any amount from zero up to your entire endowment. Any contributions to the group project will be doubled by the experimenters and shared equally by all members of the group.

For example, if you contribute $2 \mathrm{NOK}$ to the group project, this is doubled to make 4 NOK, which is then shared equally among the four members of the group. That is, if you contribute $2 \mathrm{NOK}$, you will receive one-half of this amount ( $1 \mathrm{NOK}$ ) as will each of the other three members of your group.

Similarly, each member of your group can contribute some amount to the group project, in which case it is doubled and shared equally by you and the other three members. That is, each member receives onehalf from his or her own original contribution, but the group as a whole receives twice the amount of that contribution.

\section{Earnings}

\section{[Absolute Frame Treatment A:}

In order for the group project to be implemented, the total contributions proposed by members of the group in that round must be at least 120 NOK. That is, if the sum of contributions proposed by a group is greater than or equal to $120 \mathrm{NOK}$ in a given round, the group project will be implemented in that round, and earnings will be calculated as explained above.

If, however, the sum of proposed contributions is less than 120 NOK in a given round, the group project will not be implemented in that round. In that case, your proposed contribution is not deducted from your endowment, and each member keeps his or her original endowment minus a penalty of 10 NOK per person.

In summary, if total contributions in your group equal 120 NOK or more, your earnings from this round will be:

Your earnings $=$ your endowment - your contribution $+0.5 \times($ sum of group contributions $)$

If, on the other hand, total contributions in your group equal less than $120 \mathrm{NOK}$, every member simply earns his or her endowment minus 10 NOK (either 30 NOK or 70 NOK) in this round.

Your total earnings consist of the sum of your earnings from the four paid rounds.]

\section{[Relative Frame Treatment B:}

In order for the group project to be implemented, the total contributions proposed by members of the group in that round must be at least $50 \%$ of the total endowment of the group. Since the sum of the endowments of all members equals $240 \mathrm{NOK}, 50 \%$ of the total endowment is $120 \mathrm{NOK}$. That is, if the sum of contributions proposed by a group is greater than or equal to $50 \%$ of the total endowment in a 
given round, the group project will be implemented in that round, and earnings will be calculated as explained above.

If, however, the sum of proposed contributions is less than 50\% of the total endowment in a given round, the group project will not be implemented in that round. In that case, your proposed contribution is not deducted from your endowment, and each member keeps his or her original endowment minus a penalty of 10 NOK per person.

In summary, if total contributions in your group equal 50\% or more of the total endowment, your earnings from this round will be:

Your earnings $=$ your endowment - your contribution $+0.5 \times($ sum of group contributions $)$

If, on the other hand, total contributions in your group equal less than $50 \%$ of the total endowment, every member simply earns his or her endowment minus 10 NOK (either $30 \mathrm{NOK}$ or $70 \mathrm{NOK}$ ) in this round.

Your total earnings consist of the sum of your earnings from the four paid rounds.]

\section{[Payoff Frame Treatment C:}

In order for the group project to be implemented, the members of the group must propose keeping no more than 120 NOK of the total endowment of the group. That is, if the sum of amounts kept that is proposed by a group is equal to or less than $120 \mathrm{NOK}$ in a given round, the group project will be implemented in that round, and earnings will be calculated as explained above.

If, however, the sum of proposed amounts kept is greater than 120 NOK in a given round, the group project will not be implemented in that round. In that case, your proposed contribution is not deducted from your endowment, and each member keeps his or her original endowment minus a penalty of 10 NOK per person.

In summary, if total amounts kept in your group equal 120 NOK or less, your earnings from this round will be:

Your earnings $=$ your amount kept $+0.5 \times($ sum of group contributions $)$

If, on the other hand, total amounts kept in your group equal more than 120 NOK, every member simply earns his or her endowment minus 10 NOK (either 30 NOK or 70 NOK) in this round.

Your total earnings consist of the sum of your earnings from the four paid rounds.]

\section{Examples}

Three examples may help to clarify the earnings structure.

\section{[Absolute Frame Treatment A:}

Example 1 Suppose that member 1 decides to contribute 20 NOK to the group project, member 2 contributes $0 \mathrm{NOK}$, and members 3 and 4 each contribute $20 \mathrm{NOK}$. Then the total amount contributed to the group project equals $60 \mathrm{NOK}$. Since the sum of contributions is less than $120 \mathrm{NOK}$, the project is not implemented, and all members receive only their endowments less the $10 \mathrm{NOK}$ penalty, that is, members 1 and 2 each receive 30 NOK, and members 3 and 4 each receive 70 NOK. 
Example 2 Suppose that member 1 contributes 40 NOK, member 2 contributes 0 NOK, and members 3 and 4 each contribute 40 NOK. Then the total amount contributed to the project equals 120 NOK. Since the sum of contributions equals or exceeds $120 \mathrm{NOK}$, it is doubled to make $240 \mathrm{NOK}$ and is shared equally among all four members, that is, each receives $60 \mathrm{NOK}$ from the group project. Thus, member 1 receives a total of $60 \mathrm{NOK}(40-40+60)$, member 2 receives $100 \mathrm{NOK}(40-0+60)$, and members 3 and 4 each receive 100 NOK $(80-40+60)$.

Example 3 Suppose that members 1 and 2 each contribute 10 NOK to the project and members 3 and 4 each contribute $70 \mathrm{NOK}$. Then the total amount contributed to the project equals $160 \mathrm{NOK}$. Since the sum equals $160 \mathrm{NOK}$ (and exceeds $120 \mathrm{NOK}$ ), it is doubled to make $320 \mathrm{NOK}$ and is shared equally among all four members, that is, each receives $80 \mathrm{NOK}$ from the group project. Thus, members 1 and 2 each receive a total of 110 NOK (40-10+80), and members 3 and 4 each receive a total of NOK $90(80-$ 70+80).]

\section{[Relative Frame Treatment B:}

Example 1 Suppose that member 1 decides to contribute $50 \%$ of his or her endowment to the group project, member 2 contributes $0 \%$, and members 3 and 4 each contribute $25 \%$ of their endowments. Then the total amount contributed to the group project equals $60 \mathrm{NOK}$, or $25 \%$ of the total endowment of the group. Since the sum of contributions is less than $50 \%$ of the total endowment, the project is not implemented, and all members receive only their endowments less the $10 \mathrm{NOK}$ penalty, that is, members 1 and 2 each receive 30 NOK, and members 3 and 4 each receive 70 NOK.

Example 2 Suppose that member 1 contributes $100 \%$ of his or her endowment, member 2 contributes $0 \%$, and members 3 and 4 each contribute $50 \%$ of their respective endowments. Then the total amount contributed to the project equals $120 \mathrm{NOK}$, or $50 \%$ of the total endowment of the group. Since the sum of contributions equals or exceeds $50 \%$ of the total endowment, it is doubled to make $240 \mathrm{NOK}$ and is shared equally among all four members, that is, each receives $60 \mathrm{NOK}$ from the group project. Thus, member 1 receives a total of $60 \mathrm{NOK}(40-40+60)$, member 2 receives $100 \mathrm{NOK}(40-0+60)$, and members 3 and 4 each receive 100 NOK (80-40+60).

Example 3 Suppose that members 1 and 2 each contribute $25 \%$ of their endowments to the project and members 3 and 4 each contribute $87.5 \%$ of their endowments. Then the total amount contributed to the project equals 160 NOK, or $67 \%$ of the total endowment of the group. Since the sum equals $67 \%$ of the total endowment (and exceeds 50\%), it is doubled to make $320 \mathrm{NOK}$ and is shared equally among all four members, that is, each receives 80 NOK from the group project. Thus, members 1 and 2 each receive a total of 110 NOK (40-10+80), and members 3 and 4 each receive a total of NOK $90(80-70+80)$.]

\section{[Final Payoff Frame Treatment C:}

Example 1 Suppose that member 1 decides to keep 20 NOK of his or her endowment, member 2 keeps 40 NOK, and members 3 and 4 each keep 60 NOK. Then the sum of amount kept from endowments equals 180 NOK. Since the sum of amounts kept is greater than 120 NOK, the project is not implemented, and all members receive only their endowments less the 10 NOK penalty, that is, members 1 and 2 each receive $30 \mathrm{NOK}$, and members 3 and 4 each receive 70 NOK.

Example 2 Suppose that member 1 keeps 0 NOK of his or her endowment, member 2 keeps 40 NOK, and members 3 and 4 each keep 40 NOK. Then the sum of amounts kept equals 120 NOK. Since the sum of amounts kept is equal to or less than $120 \mathrm{NOK}$, the amounts contributed (which also equal $120 \mathrm{NOK}$ ) are doubled to make $240 \mathrm{NOK}$ and are shared equally among all four members, that is, each receives $60 \mathrm{NOK}$ 
from the group project. Thus, member 1 receives a total of 60 NOK $(0+60)$, member 2 receives 100 NOK (40+60), and members 3 and 4 each receive 100 NOK (40+60).

Example 3 Suppose that members 1 and 2 each keep 30 NOK of their endowments and members 3 and 4 each keep 10 NOK. Then the sum of amounts kept equals 80 NOK. Since the sum of amounts kept equals $80 \mathrm{NOK}$ (and is less than $120 \mathrm{NOK}$ ), the amounts contributed (which equal $160 \mathrm{NOK}$ ) are doubled to make 320 NOK and are shared equally among all four members, that is, each receives 80 NOK from the group project. Thus, members 1 and 2 each receive a total of 110 NOK (30+80), and members 3 and 4 each receive a total of NOK $90(10+80)$.]

\section{Please press the "continue" button now.}

\section{Proposals}

In each round, the implementation decision and actual earnings depend on proposals. You will now see a screen where you can enter proposals for yourself and for every other member of your group. Please wait to do so until I tell you to start.

In this screen, you can propose what you wish to keep of your endowment or to contribute to the group project as well as proposing what each of the other three members of your group keeps or contributes. That is, you will make four proposals, one for each of the four members of your group. At the same time, each of the other members of your group will make four proposals for each person in the group. What you propose for yourself is binding: that is, if your binding proposal for yourself and the 3 other group members' binding proposals for themselves result in the group project being implemented, then these binding proposals will be used to calculate earnings and this round ends. Your proposals for the three other members of your group, however, are not binding: these are only suggestions.

\section{[Absolute Frame Treatment A:}

To see the total contributions and your profits that would result if your proposals were implemented, you can click on the "Preview earnings for these proposals" button. This will give you estimates that are based only on your own proposals, whereas your actual earnings will be based on the binding decisions of you and each of the other members of your group. You can repeat this with different proposals for up to three times.

When you are finished previewing different alternatives, you can submit your proposals by clicking the "Submit" button which will appear. Your proposal for yourself will then be binding. After all members have submitted, all proposals will be communicated to all members of the group. If the total contributions that result from the binding proposals equal or exceed $120 \mathrm{NOK}$, the group project is implemented and the round ends. Earnings will be calculated based on the binding proposals each member made for him- or herself.

If the total resulting binding contributions are less than $120 \mathrm{NOK}$, however, no payments or penalties are made based on these proposals. Instead, there will be a second opportunity to make proposals. Once again, you will make a proposal for yourself, which is binding, and for each of the other three members of your group, which are merely suggestions. Similarly, the other members of your group also make their proposals. If the total resulting binding contributions now equal or exceed $120 \mathrm{NOK}$, the round ends, and earnings are calculated based on the binding proposals of each member.

If total binding contributions are still less than $120 \mathrm{NOK}$, no payments will be made, and there will be a third and final opportunity to make proposals, with the same rules. Thus, there are up to three 
opportunities to make proposals in each round. If total binding contributions are still less than 120 NOK after the third and final proposal exchange, the group project is not implemented. Each member then simply earns his endowment minus a penalty of 10 NOK per person, that is, members 1 and 2 each earn 30 NOK and members 3 and 4 each earn 70 NOK.]

\section{[Relative Frame Treatment B:}

To see the percentage of the total endowment of the group contributed and your profits that would result if your proposals were implemented, you can click on the "Preview earnings for these proposals" button. This will give you estimates that are based only on your own proposals, whereas your actual earnings will be based on the binding decisions of you and each of the other members of your group. You can repeat this with different proposals for up to three times.

When you are finished previewing different alternatives, you can submit your proposals by clicking the "Submit" button which will appear. Your proposal for yourself will then be binding. After all members have submitted, all proposals will be communicated to all members of the group. If the total contributions that result from the binding proposals equal or exceed $50 \%$ of the total endowment, the group project is implemented and the round ends. Earnings will be calculated based on the binding proposals each member made for him- or herself.

If the total resulting binding group contributions are less than $50 \%$ of the total endowment, however, no payments or penalties are made based on these proposals. Instead, there will be a second opportunity to make proposals. Once again, you will make a proposal for yourself, which is binding, and for each of the other three members of your group, which are merely suggestions. Similarly, the other members of your group also make their proposals. If the total resulting binding group contributions now equal or exceed $50 \%$ of the total endowment, the round ends, and earnings are calculated based on the binding proposals of each member.

If total binding group contributions are still less than $50 \%$ of the total endowment, no payments will be made, and there will be a third and final opportunity to make proposals, with the same rules. Thus, there are up to three opportunities to make proposals in each round. If total binding group contributions are still less than 50\% after the third and final proposal exchange, the group project is not implemented. Each member then simply earns his endowment minus a penalty of 10 NOK per person, that is, members 1 and 2 each earn 30 NOK and members 3 and 4 each earn 70 NOK.]

\section{[Payoff Frame Treatment C:}

To see the sum of amounts kept of the total endowment and your profits that would result if your proposals were implemented, you can click on the "Preview earnings for these proposals" button. This will give you estimates that are based only on your own proposals, whereas your actual earnings will be based on the binding decisions of you and each of the other members of your group. You can repeat this with different proposals for up to three times.

When you are finished previewing different alternatives, you can submit your proposals by clicking the "Submit" button which will appear. Your proposal for yourself will then be binding. After all members have submitted, all proposals will be communicated to all members of the group. If total amounts kept that result from the binding proposals are equal to or less than $120 \mathrm{NOK}$, the group project is implemented and the round ends. Earnings will be calculated based on the binding proposals each member made for him- or herself. 
If the total resulting binding amounts kept are greater than $120 \mathrm{NOK}$, however, no payments or penalties are made based on these proposals. Instead, there will be a second opportunity to make proposals. Once again, you will make a proposal for yourself, which is binding, and for each of the other three members of your group, which are merely suggestions. Similarly, the other members of your group also make their proposals. If the total resulting binding amounts kept are now equal to or less than $120 \mathrm{NOK}$, the round ends, and earnings are calculated based on the binding proposals of each member.

If total binding group amounts kept are still greater than 120 NOK, no payments will be made, and there will be a third and final opportunity to make proposals, with the same rules. Thus, there are up to three opportunities to make proposals in each round. If total binding amounts kept are still greater than 120 NOK after the third and final proposal exchange, the group project is not implemented. Each member then simply earns his endowment minus a penalty of 10 NOK per person, that is, members 1 and 2 each earn 30 NOK and members 3 and 4 each earn 70 NOK.]

If there are any questions, please raise your hand now, and someone will come to you to answer your question individually.

\section{Practice round}

The first round is a practice round to help familiarize you with the experimental procedures. The instructions and procedures in the practice round are the same as in the experiment itself, except that the earnings are hypothetical. That is, the earnings for the practice round will not be paid. Remember that, in each round, there are up to three opportunities to make proposals.

The experiment will now begin. You can start entering your proposals. Please follow the instructions on the screen. After the practice round, the experiment will continue to the paid rounds. If you have questions, please raise your hand.

end of instructions

\section{To be read immediately after instructions:}

In this experiment, there may be periods of waiting time. To minimize this, please do not forget to push the "OK" or "continue" button when you are finished with a screen; otherwise everyone may be waiting for you.

\section{To be read after $5^{\text {th }}$ and final round:}

\section{ABOUT PAYMENTS}

You will now be provided with an ID number. Write this ID number on the payment form provided at your desk. The ID number will be the only remaining link between your identity and the decisions you made in the experiment. If you do not write down the ID number correctly, we will be unable to pay you. Please note also your ID number on the blank sheet of paper and keep it for your own reference. In addition to the ID number, please fill out your name, personal number (personnummer), address and bank account number. Then sign the form, place it in the provided envelope and seal the envelope. The envelopes will be sent unopened to our accountants (not the experimenters) who will transfer your earnings to your bank account. The experimenters will not know your earnings. We are required by law to 
report your earnings to the tax authorities, which is why we ask about your personal number, but you will not have to pay taxes on your earnings from this experiment.

If you do not have the information required for filling out the payment form available at the moment, you can take the form home, fill it out, and send it, after no more than 14 days, to the address provided on the form.

Before leaving, we will ask you to please answer some questions. These will appear on the screen in front of you when you are finished writing down your ID number.

\section{Questionnaire}

Please answer these questions about yourself, indicating just one answer per question.

1. What is your faculty?

1 Theology

2 Law

3 Medicine

4 Mathematics and Natural Sciences

5 Humanities

6 Dentistry

7 Social Sciences

8 Education

9 Other

10 I am not a student

2. Have you studied economics at the university level for at least one semester?

1 Yes

$2 \mathrm{No}$

3. For how long have you been a university student?

1 Less than 1 year

2 Between 1 and 2 years

3 Between 2 and 3 years

4 Between 3 and 4 years

54 years or more

4. What is your age (in years)?

5. What is your gender?

1 Male

2 Female

(Press OK) 
6. What is your best estimate of your total expenditures this school year (from mid-August to mid-May)? Please consider all expenses including housing, food, clothing, transportation, entertainment, etc., even if some are covered by financial aid or grants. State your answer in NOK for the current school year (first to last day of classes).

7. What was the total (gross) income last year of your parents or guardians? Exclude your own earnings. Please choose a single response, even if it is a guess.

10 to less than $200,000 \mathrm{NOK}$

2200,000 NOK to less than 400,000 NOK

3400,000 NOK to less than 600,000 NOK

4600,000 to less than 1000,000 NOK

51000,000 to less than $1500,000 \mathrm{NOK}$

61500,000 NOK or more

8. How many hours per week do you have paid work, on average (enter 0 if none)?

9. Approximately how much money have you earned total through your work over the past year (the past twelve months) in NOK?

NOK

(Press $O K)$

(Absolute Frame Treatment A)

What amounts of their endowments do you think each of the members of your group should have contributed?

Member 1 with endowment 40

Member 2 with endowment $40 \quad$ (four fields for numbers)

Member 3 with endowment 80

Member 4 with endowment 80

Which of the following sets do you think is most fair?

A B C (three fields to check off one of the three on left)

A $\quad$ B $\quad$ C

Member 1 with endowment $40 \quad 30 \quad 20 \quad 10$

Member 2 with endowment $40 \quad 30 \quad 20 \quad 10$

Member 3 with endowment $80 \quad 30 \quad 40 \quad 50$

Member 4 with endowment $80 \quad 30 \quad 40 \quad 50$

Select one of the three sets of amounts contributed.

(Press OK)

Suppose you could have made your proposals binding on all members of your group in the experiment. That is, suppose all payoffs are based on your proposals alone and the proposals of 
the other members do not count. What amounts would you choose for each member of your group to contribute?

Member 1 with endowment 40

Member 2 with endowment 40

(four fields for numbers)

Member 3 with endowment 80

Member 4 with endowment 80

Why did you make the proposals you did for yourself and the members of your group in the experiment (feel free to respond in Norwegian)?

(space for open response)

\section{(Relative Frame Treatment B)}

What percentages of their endowments do you think each of the members of your group should have contributed?

Member 1 with endowment 40

Member 2 with endowment $40 \quad$ (four fields for numbers)

Member 3 with endowment 80

Member 4 with endowment 80

Which of the following sets of decisions do you think is most fair? Select one of the three sets of percentages contributed.

A $\quad$ B $\quad$ C (three fields to check off one of the three on left)

$\begin{array}{llll} & \text { A } & \text { B } & \text { C } \\ \text { Member 1 with endowment 40 } & 75.0 & 50.0 & 25.0 \\ \text { Member 2 with endowment 40 } & 75.0 & 50.0 & 25.0 \\ \text { Member 3 with endowment 80 } & 37.5 & 50.0 & 62.5 \\ \text { Member 4 with endowment 80 } & 37.5 & 50.0 & 62.5\end{array}$

\section{(Press OK)}

Suppose you could have made your proposals binding on all members of your group in the experiment. That is, suppose all payoffs are based on your proposals alone and the proposals of the other members do not count. What percentages would you choose for each member of your group to contribute?

Member 1 with endowment 40

Member 2 with endowment $40 \quad$ (four fields for numbers)

Member 3 with endowment 80

Member 4 with endowment 80

Why did you make the proposals you did for yourself and the members of your group in the experiment (feel free to respond in Norwegian)?

(space for open response)

(Payoff Frame Treatment C)

What amounts of their endowments do you think each of the members of your group should have kept? 
Member 1 with endowment 40

Member 2 with endowment 40

(four fields for numbers)

Member 3 with endowment 80

Member 4 with endowment 80

Which of the following sets of decisions do you think is most fair? Select one of the three sets of amounts kept.

A B C (three fields to check off one of the three on left)

$\begin{array}{llll} & \text { A } & \text { B } & \text { C } \\ \text { Member 1 with endowment 40 } & 10 & 20 & 30 \\ \text { Member 2 with endowment 40 } & 10 & 20 & 30 \\ \text { Member 3 with endowment 80 } & 50 & 40 & 30 \\ \text { Member 4 with endowment 80 } & 50 & 40 & 30\end{array}$

(Press $O K)$

Suppose you could have made your proposals binding on all members of your group in the experiment. That is, suppose all payoffs are based on your proposals alone and the proposals of the other members do not count. What amounts would you choose for each member of your group to keep?

Member 1 with endowment 40

Member 2 with endowment $40 \quad$ (four fields for numbers)

Member 3 with endowment 80

Member 4 with endowment 80

Why did you make the proposals you did for yourself and the members of your group in the experiment (feel free to respond in Norwegian)?

Thank you for your participation! 


\section{APPENDIX B}

Additional tables

Table A1. OLS regressions of contributions, controlling for gender, income and parents' income.

\begin{tabular}{|c|c|c|}
\hline & $\begin{array}{c}\text { (1) } \\
\text { Absolute } \\
\text { contribution }\end{array}$ & $\begin{array}{c}\text { (2) } \\
\text { Relative } \\
\text { contribution }\end{array}$ \\
\hline LxAC & $\begin{array}{l}7.435^{* * * *} \\
(2.067)\end{array}$ & $\begin{array}{l}0.187^{* * * *} \\
(0.0523)\end{array}$ \\
\hline LxRC & $\begin{array}{l}4.178^{*} \\
(2.501)\end{array}$ & $\begin{array}{c}0.103 \\
(0.0632)\end{array}$ \\
\hline LxRK & $\begin{array}{c}0.732 \\
(2.245)\end{array}$ & $\begin{array}{c}0.0209 \\
(0.0549)\end{array}$ \\
\hline High & $\begin{array}{c}25.86^{* * * *} \\
(3.318)\end{array}$ & $\begin{array}{c}0.0270 \\
(0.0571)\end{array}$ \\
\hline $\mathrm{HxAC}$ & $\begin{array}{c}2.810 \\
(4.141)\end{array}$ & $\begin{array}{c}0.0345 \\
(0.0522)\end{array}$ \\
\hline HxRC & $\begin{array}{c}3.670 \\
(4.556)\end{array}$ & $\begin{array}{c}0.0476 \\
(0.0570)\end{array}$ \\
\hline HxRK & $\begin{array}{c}6.438 \\
(3.977)\end{array}$ & $\begin{array}{c}0.0808 \\
(0.0497)\end{array}$ \\
\hline Male & $\begin{array}{c}1.024 \\
(1.685)\end{array}$ & $\begin{array}{c}0.0191 \\
(0.0273)\end{array}$ \\
\hline Expenditures & $\begin{array}{c}-0.207 \\
(0.865)\end{array}$ & $\begin{array}{l}0.00908 \\
(0.0140)\end{array}$ \\
\hline Parents' inc. & $\begin{array}{c}-135.6 \\
(194.8)\end{array}$ & $\begin{array}{l}-2.850 \\
(3.151)\end{array}$ \\
\hline Round & $\begin{array}{c}-1.103^{* * * *} \\
(0.376)\end{array}$ & $\begin{array}{l}-0.0166^{* * *} \\
(0.00640)\end{array}$ \\
\hline Constant & $\begin{array}{l}25.94^{* * *} \\
(2.519)\end{array}$ & $\begin{array}{l}0.622^{* * *} \\
(0.0535)\end{array}$ \\
\hline $\begin{array}{l}N \\
\operatorname{adj} . R^{2}\end{array}$ & $\begin{array}{c}1022 \\
0.384\end{array}$ & $\begin{array}{l}1022 \\
0.035\end{array}$ \\
\hline
\end{tabular}

Notes: The dependent variable in Column 1 is absolute contributions in NOK and relative contributions in Column 2. The reference category is AK. Expenditures is the subject's reported total expenditures, in $1000 \mathrm{NOK}$, during the school year. Parents' income is total gross income of parents in 100000 NOK last year, using average of income brackets as point estimate. For the top bracket; above 1500000 NOK (5.75\% of observations) we used the point estimate 1750000 NOK. Standard errors appear in parentheses, and statistical significance is indicated as ${ }^{*} p<0.1$, ${ }^{* *} p<0.05,{ }^{* * *} p<0.01$. Standard errors are clustered on group. Due to a technical error during the experiment, two observations from the RC treatment are not included. Only payoff-relevant periods are included. 
Table A2. OLS regressions of contributions on questionnaire responses, lagged suggestions and lagged behavior.

\begin{tabular}{|c|c|c|c|c|}
\hline & $(1)$ & (2) & (3) & (4) \\
\hline \multirow[t]{2}{*}{ Constant } & $25.50^{* * *}$ & $9.505^{* * *}$ & $8.285^{* *}$ & $9.633^{* * *}$ \\
\hline & (1.819) & $(2.749)$ & (3.364) & $(3.568)$ \\
\hline \multirow[t]{2}{*}{ LxAC } & $7.301^{* * * *}$ & $4.768^{* *}$ & $4.032^{*}$ & $4.460^{* *}$ \\
\hline & $(2.134)$ & $(2.082)$ & $(2.218)$ & $(2.186)$ \\
\hline \multirow[t]{2}{*}{ LxRC } & 3.961 & $4.591^{*}$ & 2.671 & 2.771 \\
\hline & $(2.516)$ & $(2.384)$ & (3.649) & (3.618) \\
\hline \multirow[t]{2}{*}{ LxRK } & 0.796 & $-3.486^{*}$ & $-4.059^{*}$ & $-3.568^{*}$ \\
\hline & $(2.160)$ & $(2.028)$ & (2.189) & $(2.135)$ \\
\hline \multirow[t]{2}{*}{ High } & $25.65^{* * * *}$ & $6.461^{*}$ & 5.974 & $6.342^{*}$ \\
\hline & $(3.431)$ & $(3.730)$ & $(3.668)$ & $(3.631)$ \\
\hline \multirow[t]{2}{*}{$\mathrm{HxAC}$} & 2.813 & 0.101 & -0.415 & -0.910 \\
\hline & $(4.172)$ & $(2.737)$ & $(3.031)$ & $(2.945)$ \\
\hline \multirow[t]{2}{*}{ HxRC } & 3.715 & 0.662 & -0.940 & -1.651 \\
\hline & $(4.579)$ & $(3.071)$ & (3.718) & $(3.851)$ \\
\hline \multirow[t]{2}{*}{ HxRK } & 6.621 & 1.587 & 1.446 & 1.397 \\
\hline & $(4.025)$ & $(2.813)$ & $(2.947)$ & $(2.920)$ \\
\hline \multirow[t]{2}{*}{ Round } & $-1.102^{* * *}$ & $-1.103^{* * *}$ & $-1.138^{* * * *}$ & $-1.142^{* * *}$ \\
\hline & $(0.376)$ & $(0.376)$ & $(0.394)$ & $(0.396)$ \\
\hline \multirow{2}{*}{$\begin{array}{l}\text { Fair contr. for } \\
\text { self }\end{array}$} & & $0.170^{*}$ & $0.174^{*}$ & $0.166^{*}$ \\
\hline & & $(0.0949)$ & $(0.0971)$ & $(0.0983)$ \\
\hline \multirow[t]{2}{*}{ Should } & & $0.404^{* * *}$ & $0.410^{* * *}$ & $0.425^{* * *}$ \\
\hline & & $(0.0604)$ & $(0.0602)$ & $(0.0604)$ \\
\hline \multirow[t]{2}{*}{ Dictate } & & $0.130^{* * * *}$ & $0.122^{* * * *}$ & $0.116^{* * * *}$ \\
\hline & & $(0.0456)$ & $(0.0434)$ & $(0.0434)$ \\
\hline \multirow{2}{*}{$\begin{array}{l}\text { Lagged sugg. } \\
\text { by same type }\end{array}$} & & & -0.0396 & -0.0454 \\
\hline & & & $(0.0374)$ & $(0.0372)$ \\
\hline \multirow{2}{*}{$\begin{array}{l}\text { Lagged sugg. } \\
\text { by other type }\end{array}$} & & & 0.0129 & 0.0137 \\
\hline & & & $(0.0446)$ & $(0.0445)$ \\
\hline \multirow{2}{*}{$\begin{array}{l}\text { Lagged contr. } \\
\text { by same type }\end{array}$} & & & $0.0605^{*}$ & $0.0650^{*}$ \\
\hline & & & $(0.0353)$ & $(0.0341)$ \\
\hline \multirow{2}{*}{$\begin{array}{l}\text { Lagged contr. } \\
\text { by other type }\end{array}$} & & & 0.0188 & 0.0253 \\
\hline & & & $(0.0444)$ & $(0.0451)$ \\
\hline Male & & & & $\begin{array}{l}-0.977 \\
(1.273)\end{array}$ \\
\hline \multirow{2}{*}{ Expenditures } & & & & 0.425 \\
\hline & & & & $(0.753)$ \\
\hline \multirow[t]{2}{*}{ Parents' income } & & & & -235.0 \\
\hline & & & & $(144.3)$ \\
\hline$N$ & 1022 & 1022 & 1022 & 1022 \\
\hline $\operatorname{adj} . R^{2}$ & 0.385 & 0.528 & 0.530 & 0.531 \\
\hline
\end{tabular}

Notes: The dependent variable is absolute contributions (NOK). The reference category is AK. Standard errors appear in parentheses, and statistical significance is indicated as ${ }^{*} p<0.1,{ }^{* *} p<0.05,{ }^{* * *} p<0.01$. Standard errors 
are clustered on group. Due to a technical error during the experiment, two observations from the RC treatment are missing. Fair contr. for self is the contribution for the subject herself implied by her answer to the question "Which of the following sets of decisions do you think is most fair?" where the response alternatives are indicated in Table 2. Should is the contribution for the subject herself implied by her response to the question "What percentages of their endowments do you think each of the members of your group should have contributed?". Dictate is the contribution for the subject herself implied by her response to the question "Suppose you could have made your proposals binding on all members of your group in the experiment. That is, suppose all payoffs are based on your proposals alone and the proposals of the other members do not count. What amounts would you choose for each member of your group to keep?" Expenditures is the subject's reported total expenditures, in 1000 NOK, during the school year. Parents' income is total gross income of parents in 100000 NOK last year, using average of income brackets as point estimate. For the top bracket; above 1500000 NOK (5.75\% of observations) we used the point estimate $1750000 \mathrm{NOK}$. Lagged variables are lagged one period, including, for suggestions only, payoff-irrelevant periods. Otherwise only payoff-relevant periods are included.

\section{Table A3: Mean contributions by self and suggestions for others (NOK) by endowment and treatment}

$\begin{array}{llllll} & & \text { AC } & \text { RC } & \text { AK } & \text { RK } \\ \text { High } & \text { Self } & 52.3 & 53.2 & 49.5 & 56.1 \\ & \text { Other High } & 59.1 & 59.2 & 55.9 & 60.4 \\ & \text { Average Low } & 32.9 & 31.2 & 27.0 & 28.9 \\ \text { N=128 } & & & & \\ \text { Low } & 31.1 & 27.8 & 23.8 & 24.6 \\ \text { Self } & 33.4 & 30.7 & 25.5 & 26.5 \\ & \text { Other Low } & 63.1 & 63.4 & 58.6 \\ \text { Average High } & 66.1 & 64.7 & & \\ \text { N=128 } & & & \end{array}$

Notes: Binding proposals for oneself (contributions) and non-binding suggestions for other group members by high endowed subjects (upper part of table) and low endowed (lower part). Contributions and suggestions are measured in absolute units (NOK). Only payoff-relevant periods are included. 